\title{
Are UV filters polluting our beaches? A field study of French Mediterranean beach from consumer survey to water analysis
}

JeROME LABILle1, *, DANIELle SLOMBERG1, RiCCARDO CATAlano1, SAmuel Robert2, MARIE-LAURE APERSTREMELO2, JEAN-LUC BoUdENNE3, TAREK MANASFI3, OLIVIER RADAKOVITCH 1,4

1 Aix Marseille Univ, CNRS, IRD, INRA, Coll France, CEREGE, Aix-en-Provence, France

2 Aix-Marseille Univ, Avignon Univ, Univ Côte d'Azur, CNRS, ESPACE, Avignon, France

3 Aix Marseille Univ, CNRS, LCE UMR7376, Marseille, France

4 Institut de Radioprotection et de Sûreté Nucléaire (IRSN). PSE-ENV/SRTE/LRTA, BP 13, 13115 Saint Paul les durance, France

Sunscreens are of emerging concern regarding both human and environmental health due to the potential risks related to UV filters. In 2018, Hawai state baned some chemical UV filters to limit their impact on the marine environment. Recently, these molecules were also shown to pass the skin barrier and reach the consumer's blood.

In order to assess the release of UV filters from the beachgoers' skin into seawater, we carried out a field campaign on Marseille beach, French Mediterranean coast. A social survey analyzed beachgoer attendance, the quantities and types of suncare products used and the bathing frequencies, while the bathing water was analyzed spatially so as to quantify both mineral and organic UV filters released.

During the peak recreational time, both mineral and organic UV filters were detected in higher concentrations in the bathing area than offshore. Higher concentrations were recovered in the water top surface layer than in the water column, giving respectively $\mathrm{TiO}_{2}$ at $100-900$ and $20-50 \mu \mathrm{g} / \mathrm{L}$, $\mathrm{ZnO}$ at $10-15$ and $1-3 \mu \mathrm{g} / \mathrm{L}$ octocrylene at $40-420$ and $30-150$ $\mathrm{ng} / \mathrm{L}$, and avobenzone at $10-15$ and 10-350 $\mathrm{ng} / \mathrm{L}$.

From the survey, we estimated that an average mass of 52 $\mathrm{kg} /$ day of sunscreen, or $16 \mathrm{~kg}$ /day of UV filter, are possibly released into bathing water for a beach attended by 3,000 people daily. Our recovery of measured UV filter concentrations in seawater compared to the predicted concentrations revealed two distinct scenarios for the mineral and organic filters. While up to $49 \%$ of the mineral filters used by beachgoers may be released into the seawater, the organic filters were minimally recovered in the environment, most likely due to internalization through the skin barrier or partial photodegradation. (Work funded by Labex DRIIHM) 